\title{
Regulation of cell cycle transition and induction of apoptosis in HL-60 leukemia cells by lipoic acid: role in cancer prevention and therapy
}

\author{
Elangovan Selvakumar and Tze-chen Hsieh*
}

\author{
Address: Department of Biochemistry and Molecular Biology, New York Medical College, Valhalla, New York 10595, USA \\ Email: Elangovan Selvakumar - eselva@gmail.com; Tze-chen Hsieh* - Tze-chen_Hsieh@nymc.edu \\ * Corresponding author
}

Published: 30 May 2008

Journal of Hematology \& Oncology 2008, I:4 doi:10.1 186/1756-8722-I-4

This article is available from: http://www.jhoonline.org/content/I/I/4

(C) 2008 Selvakumar and Hsieh; licensee BioMed Central Ltd.

This is an Open Access article distributed under the terms of the Creative Commons Attribution License (http://creativecommons.org/licenses/by/2.0), which permits unrestricted use, distribution, and reproduction in any medium, provided the original work is properly cited.
Received: 30 April 2008

Accepted: 30 May 2008

\begin{abstract}
Background: Lipoic acid (LA), a potent antioxidant, has been used as a dietary supplement to prevent and treat many diseases, including stroke, diabetes, neurodegenerative and hepatic disorders. Recently, potent anti-tumorigenic effects induced by LA were also reported and evident as assayed by suppression of cell proliferation and induction of apoptosis in malignant cells. However, the mechanism by which LA elicits its chemopreventive effects remains unclear.

Methods and Results: Herein, we investigated whether LA elicits its anti-tumor effects by inducing cell cycle arrest and cell death in human promyelocytic HL-60 cells. The results showed that LA inhibits both cell growth and viability in a time- and dose-dependent manner. Disruption of the $G_{1} / S$ and $G_{2} / M$ phases of cell cycle progression accompanied by the induction of apoptosis was also observed following LA treatment. Cell cycle arrest by LA was correlated with dose-dependent down regulation of $\mathrm{Rb}$ phosphorylation, likely via suppression of E2F-dependent cell cycle progression with an accompanying inhibition of cyclin $\mathrm{E} / \mathrm{cdk} 2$ and cyclin $\mathrm{BI} / \mathrm{cdk} \mathrm{I}$ levels. Evidence supporting the induction of apoptosis by LA was based on the appearance of sub-G, peak in flow cytometry analysis and the cleavage of poly(ADP-ribose) polymerase (PARP) from its native II2$\mathrm{kDa}$ form to the $89-\mathrm{kDa}$ truncated product in immunoblot assays. Apoptosis elicited by LA was preceded by diminution in the expression of anti-apoptotic protein bcl-2 and increased expression of apoptogenic protein bax, and also the release and translocation of apoptosis inducing factor AIF and cytochrome $c$ from the mitochondria to the nucleus, without altering the subcellular distribution of the caspases.
\end{abstract}

Conclusion: This study provides evidence that LA induces multiple cell cycle checkpoint arrest and caspase-independent cell death in HL-60 cells, in support of its efficacious potential as a chemopreventive agent.

\section{Background}

$\alpha$-Lipoic acid (LA), also known as thioctic acid, occurs naturally as a prosthetic group in various mitochondrial enzymatic complexes and plays a fundamental role in metabolism. It is involved in different multienzyme complexes such as pyruvate dehydrogenase, $\alpha$-ketoglutarate dehydrogenase, branched-chain $\alpha$-keto acid dehydrogenase, and glycine decarboxylase complex [1]. The two sul- 
fur molecules in LA undergo cycles of oxidation and reduction, enabling it to function as a potent antioxidant that is capable of directly terminating potentially damaging free radicals. Several features have been described for LA such as (a) specificity of free radical scavenging in both oxidized and reduced forms, (b) interaction with other antioxidants, (c) metal-chelating activity, (d) effects on gene expression, (e) bioavailability, (f) location (in aqueous or membrane domains, or both), and (g) ability to repair oxidative damage, which make it an outstanding antioxidant [2-4]. Added to cell culture medium in vitro, LA readily enters cells and is reduced by mitochondrial and cytosolic enzymes to dihydrolipoic acid, most of which is rapidly effluxed from the cell to the culture medium [5]. Experimental and clinical studies have indicated the potential usefulness of exogenous LA as a therapeutic agent for the prevention and treatment of various pathologies including diabetes [6], atherosclerosis [7], ischemia-reperfusion injury [8], degenerative processes in neurons [9], diseases of joints [10], radiation injury [11], heavy metal poisoning [12] and HIV activation [13]. LA is readily absorbed from the diet, and to date, only mild side effects have been detected following LA administration; supports the overall feasibility of using LA as a dietary supplement [3].

In recent years, LA has gained considerable attention in the cancer field as an anticancer agent $[14,15]$. Results from antiproliferation studies on cancerous cell-based models have suggested that the tumor-suppressive effect of LA corresponds with apoptosis induction, a critical parameter impaired in cancer cells, and this induction is selectively exerted in cancer and transformed cell lines, while being less active toward normal nontransformed cells [16-18]. Thus, LA was shown to induce apoptosis in tumor Jurkat, FaDu, Ki-v-Ras-transformed mesenchymal cells and human lung epithelial cancer H460 cells $[19,20]$. In human leukemic T cells, LA also potentiated Fas-mediated apoptosis through redox regulation without affecting peripheral blood monocytes from healthy humans [21]. In experiments using antioxidant response element (ARE) reporter assays, LA has also been shown to induce phase II protective genes which are involved in the prevention of carcinogenesis, in non-cancerous animal- and cell-based studies [22-24]. These studies support the potential utility of LA as an anticancer agent and the importance of the elucidation of the detailed mechanism of its antitumor activity. Because of its widespread use and therapeutic potential of LA, however, the mechanism by which LA elicits its chemopreventive effects remains largely unknown.

We sought to determine the LA-induced apoptosis and cell cycle arrest and the underlying mechanisms of action. Our study shows for the first time that LA is capable to block multiple cell cycle checkpoints including $G_{1} / S$ and $\mathrm{G}_{2} / \mathrm{M}$ and induce caspase-independent cell death via AIF/ cytochrome $\mathrm{c}$ translocation from the mitochondria to the nucleus. Our findings provide mechanistic support to the potential utility of LA as an agent for the treatment of leukemia.

\section{Materials and methods Reagents}

DL- $\alpha$-Lipoic acid was purchased from LKT laboratories (St Paul, MN). Primary antibodies like anti-Rb, anti-E2F, anticyclin $\mathrm{B} 1$, anti-cyclin $\mathrm{D}$, anti-cyclin $\mathrm{E}$, anti-cdk1, anticdk2, anti-AIF, anti-cytochrome c, anti-bcl-2, anti-bax, anti-actin, anti-histone $\mathrm{H} 1$, and secondary antibodies were purchased from Santa Cruz Biotechnology, Inc. (Santa Cruz, CA). Primary antibodies like anti-pRb (ser 780) and anti-pRb (ser 807/811) were purchased from Biosource International, Inc. (Camarillo, CA). Anti-PARP was purchased from Biomol International, L.P. (Plymouth Meeting, PA). Fetal calf serum, RPMI 1640, penicillin and streptomycin were purchased from Cellgro, Inc (Herndon, VA). All other chemicals and solvents used were of analytical grade.

\section{Cell culture and growth inhibition assay}

Human HL-60 cells were obtained from American Tissue Culture Collection (Manassas, VA) and maintained in RPMI 1640 supplemented with penicillin, streptomycin and $10 \%$ heat inactivated fetal calf serum as previously described [25-27]. For treatment, cells were seeded at a density of $1 \times 10^{5}$ cells $/ \mathrm{ml}$. LA dissolved in $1 \mathrm{~N} \mathrm{NaOH}$ solution and neutralized with $\mathrm{HCl}$, was added to the culture media to the final concentration specified in the text. At the specified times, control and treated cells were harvested. Cell count was performed using a hemocytometer and cell viability was determined by trypan blue exclusion [25-27]. Harvested cells were washed twice with PBS, and pellets were stored at $-80^{\circ} \mathrm{C}$ for additional biochemical and molecular analyses.

\section{Cell cycle analysis}

Cell cycle phase distribution was assayed by flow cytometry. Following 24 and $48 \mathrm{~h}$ treatment of HL-60 cells with different concentrations of LA $(0,2.5$, and $5 \mathrm{mM})$, cells were washed with PBS and stained with $1.0 \mu \mathrm{g} / \mathrm{ml}$ DAPI containing $100 \mathrm{mM} \mathrm{NaCl}, 2 \mathrm{mM} \mathrm{MgCl}_{2}$ and $0.1 \%$ Triton $\mathrm{X}-100$ (Sigma) at pH 6.8 , as described $[26,28,29]$. The DNA-specific DAPI fluorescence was excited with UV light emitting laser (Ni-Cad), and collected with appropriate filters in an ICP-22 (Ortho Diagnostic, Westwood, MA) flow cytometer. MultiCycle software from Phoenix Flow Systems (San Diego, CA) was used to deconvolute the cellular DNA content histograms to obtain quantitation of the percentage of cells in the respective phases $\left(G_{1}, S\right.$ and $\mathrm{G}_{2} / \mathrm{M}$ ) of the cell cycle. Flow cytometry was also used to 
show cells undergoing apoptosis, evident by the appearance of the sub- $G_{1}$ peak $[26,28,29]$.

\section{Preparation of whole cell extracts and subcellular fractionation}

For immunoblotting experiments, cells were collected by centrifugation and were lysed in ice-cold RIPA buffer (50 $\mathrm{mM}$ Tris, $\mathrm{pH} 7.4,150 \mathrm{mM} \mathrm{NaCl}, 1 \mathrm{mM}$ EDTA, 1\% Triton $\mathrm{X}-100,1 \%$ deoxycholate, $0.1 \%$ SDS, $1 \mathrm{mM}$ dithiothreitol and $10 \mu \mathrm{l} / \mathrm{ml}$ protease inhibitor cocktail). The extracts were centrifuged and the clear supernatants were stored in aliquots at $-70^{\circ} \mathrm{C}$ for further analysis. Subcellular fractionation was performed using mitochondria isolation kit obtained from Sigma (Sigma Chemicals, St Louis, MO) and different compartmental proteins were used to study the translocation of AIF and cytochrome c. Protein content of cell lysates and subcellular fractions was determined by coomassie protein assay kit (Pierce, Rockford, IL) with BSA as standard.

\section{Immunoblotting}

The aliquots of lysates ( $20 \mu \mathrm{g}$ of protein) were boiled with sample buffer for $5 \mathrm{~min}$, and resolved by 10\% SDS-PAGE. The proteins were transferred to a nitrocellulose membrane and blocked in TBST buffer (10 mM Tris, pH 7.5, $100 \mathrm{mM} \mathrm{NaCl}$ and $0.05 \%$ Tween 20) containing 3\% nonfat dried milk overnight at $4{ }^{\circ} \mathrm{C}$. The blots were incubated with various primary antibodies, followed by incubation for $1 \mathrm{~h}$ with appropriate secondary antibodies conjugated to horseradish peroxidase in TBST. Actin and histone expression was used as loading control. Fractionation of the mitochondrial and nuclear proteins was confirmed by probing the membrane for mitochondrial specific cytochrome c oxidase antibody or nuclear specific histone H1 using their specific antibodies. The intensity of the specific immunoreactive bands were detected by enhanced chemiluminescence (ECL), using the manufacturer's protocol (Kirkegared \& Perry Laboratories) and quantified by densitometry and expressed as a ratio to actin or histone, as previously described [27].

\section{Results}

Inhibition of HL-60 cell growth by LA is both time and dose dependent

Initially, we investigated the effect of LA on cell growth inhibition. Exponentially growing HL-60 cells were treated with increasing doses and exposure times of LA, and subjected to trypan blue exclusion assay to measure the cell growth and viability. LA treatment resulted in dose- and time-dependent inhibition of cell growth, compared with controls, and the magnitude of cell growth suppression was seen as early as $24 \mathrm{~h}$ exposure to $5 \mathrm{mM}$ LA (89\%; Fig. 1A). By 48 h there was a 8\%, 64\% and $86 \%$ diminution of cell growth by 1, 2.5 and $5 \mathrm{mM} \mathrm{LA}$, respectively, which was accompanied by $\sim 1, \sim 3 \%$ and
A
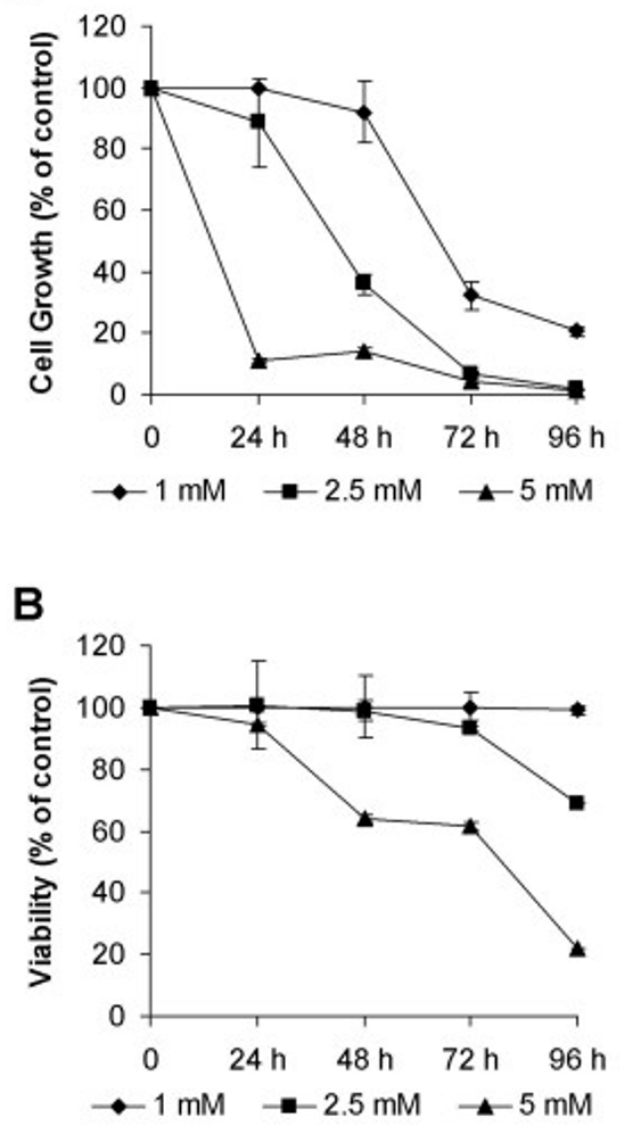

Figure I

Control of cell growth and viability in HL-60 cells by LA. (A) Cells were treated with $0,1,2.5$ and $5 \mathrm{mM}$ LA and the cell numbers were determined at 24, 48, 72 and 96 h. (B) Cell viability was measured using the trypan blue dye exclusion assay. Effects of LA were presented as a percentage of control, and values are expressed as mean \pm SD for three experiments.

$36 \%$ temporal, dose-dependent decrease in cell viability (Fig. 1B).

\section{$L A$ induces $H L-60$ cell cycle arrest by altering the expressions of specific signaling proteins}

To assess LA-induced cell growth suppression is mediated via alterations in cell cycle, we evaluated the cell cycle distribution by flow cytometry. Since $48 \mathrm{~h}$ treatment with 1 mM LA showed minimum affects on cell growth and viability, only cells exposed to 2.5 and $5 \mathrm{mM}$ LA for 24 and $48 \mathrm{~h}$ were analyzed. The percentage of cells in $\mathrm{G}_{1}, \mathrm{~S}$, and $G_{2}$ phases were calculated and presented as histograms in Fig. 2A. LA caused a significant decrease in S-phase cell population (55.6\% in control vs. $19.8 \%$ and $4.7 \%$ in cells treated with 2.5 and $5 \mathrm{mM}$ LA, respectively), accompanied 


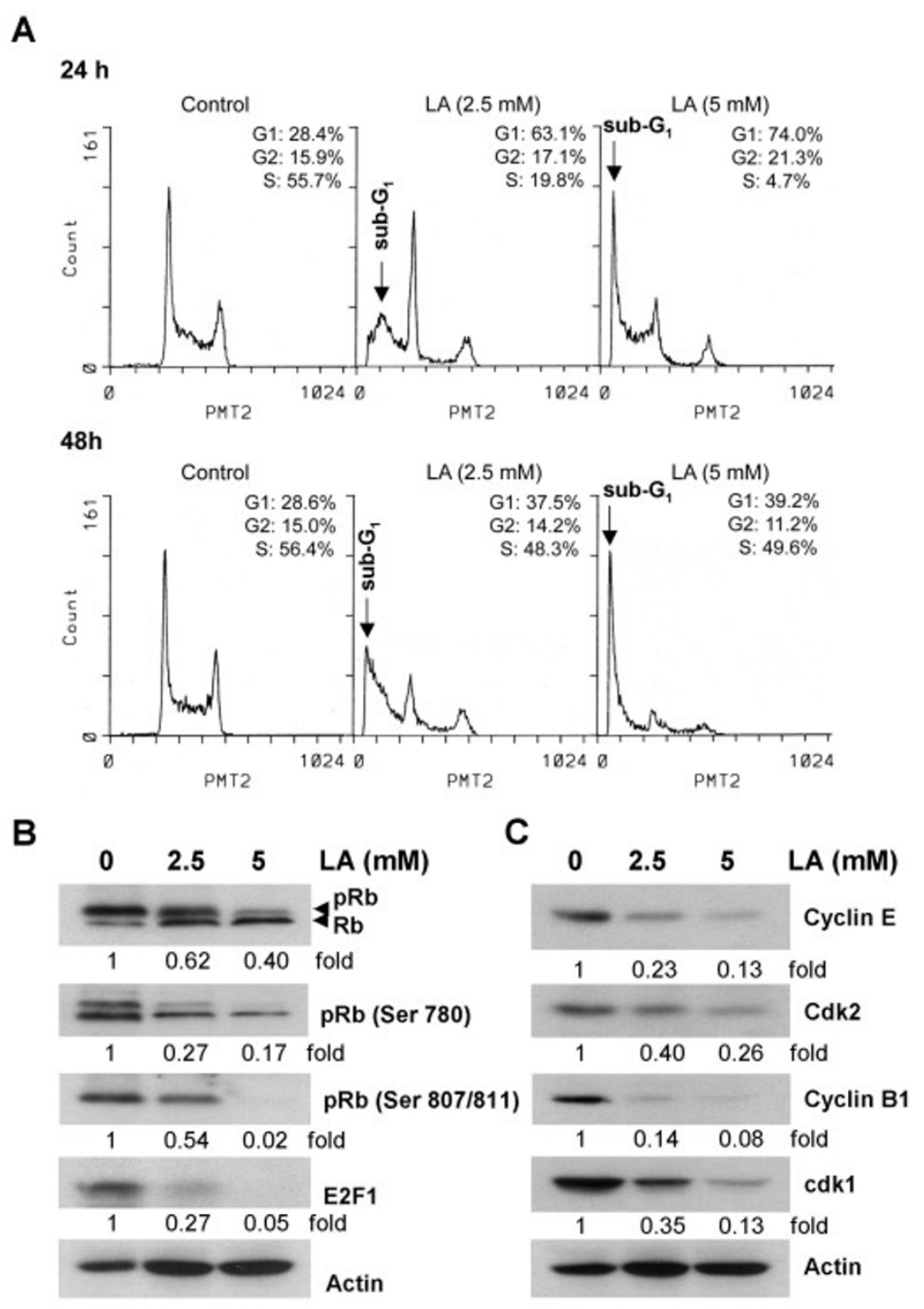

\section{Figure 2}

Effects of LA on cell cycle phase distribution and the expression of various cell cycle regulatory proteins in HL-60 cells. (A)

Cells were treated with $0,2.5$ and $5 \mathrm{mM}$ LA for 24 and $48 \mathrm{~h}$ and analyzed by flow cytometry. Cells with hypodiploid DNA content (sub- $G_{l}$ ) represent apoptotic cell fractions. (B) Western blot analysis of total Rb, pRB (ser780), pRB (ser 807/8I I) and E2F expression in cell lysate treated with LA for $48 \mathrm{~h}$. (C) The level of immunoreactive cyclins BI, E, cdkI and cdk2 in LA-treated HL-60. The intensity of the specific immunoreactive bands were quantified by densitometry and expressed as a fold difference against actin.

by a concomitant accumulation in the $\mathrm{G}_{1}$ phase cell population $(28.4 \%$ in control vs. $63.1 \%$ and $74 \%$ in 2.5 and $5 \mathrm{mM}$ LA treated cells). To further explore the cell cycle arrest by LA in HL-60 cells, specific cell cycle regulatory proteins required for $G_{1}, G_{1} / S$ and $S$ phase transition were measured by Westerm blot analysis. First, we measured the expressions of cyclins D, E and cdk2, as they play a pivotal role in controlling the phosphorylation status of $\mathrm{Rb}$, which in turn activate transcription factor E2F to induce cell entry into the S-phase. Results in Fig. 2B show that LA treatment caused a dose-dependent reduction in cyclin E/ cdk2 expression without affecting cyclin D1 (data not shown), and at the same time LA treatment also resulted in $\sim 38$ to $60 \%$ suppression of the phosphorylated $\mathrm{Rb}$ $(\mathrm{pRb})$. Moreover, LA caused a significant reduction in the phosphrylation of $\mathrm{Rb}$ at two specific sites, Ser-780 and Ser-807/811, was also observed (Fig. 2B). In addition, a more pronounced decrease in the expression of E2F was 
also detected in the treated cells (Fig. 2B), suggesting that these changes collectively contributed to the decrease in $S$ phase cell population by LA (Fig. 2A).

Since LA-treated cells also show alterations in $\mathrm{G}_{2} / \mathrm{M}$ progression, we also assayed the expression of cyclins $\mathrm{A}, \mathrm{B}$ and cdk1 expression and observed a dose-dependent down regulation of cyclin B1/cdk2 (Fig. 2C) without a corresponding alteration in the expression of cyclin $\mathrm{A}$ (data not shown).

A

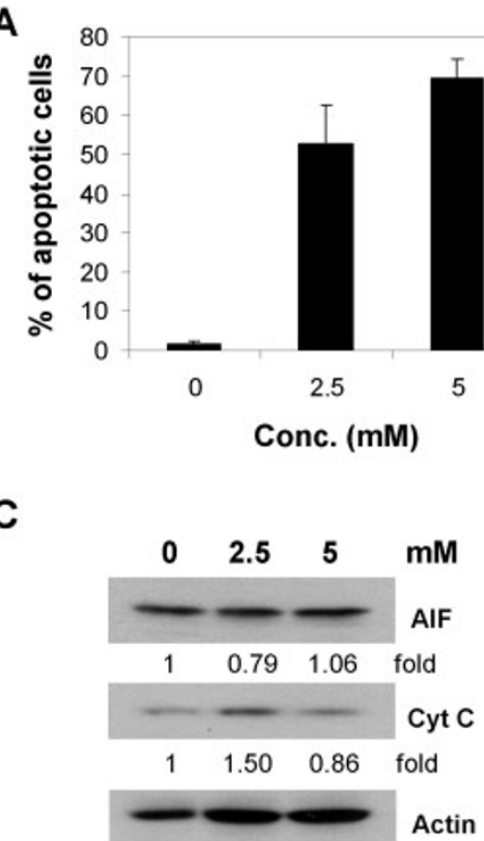

E

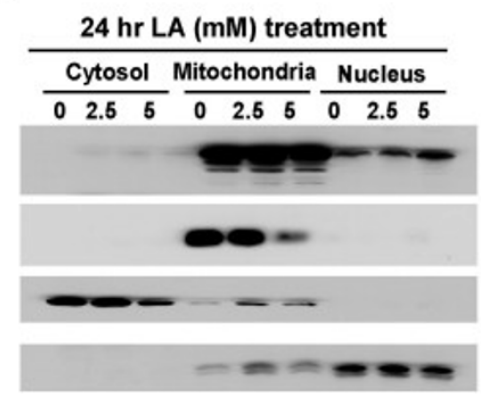

\section{LA induces apoptosis by increasing bax/bcl2 ratio and by} causing poly(ADP-ribose) polymerase (PARP) cleavage

Cell cycle analysis revealed that LA apparently induced apoptosis as evident by the appearance of sub- $\mathrm{G}_{1}$ fraction (Fig. 2A); notably, the percentage of apoptotic cells increased from $1.4 \%$ in control cells to $59.6 \%$ and $72.9 \%$ in 24 and $48 \mathrm{~h}, 2.5$ and $5 \mathrm{mM}$ LA-treated cells, which might contribute to the growth inhibitory effects of LA (Fig. 3A). Corroborative evidence of induction of apoptosis was obtained by biochemical analysis showing that PARP cleavage was substantially increased in cells treated for $48 \mathrm{~h}$ with increasing doses of LA (Fig. 3B). As addi-

B

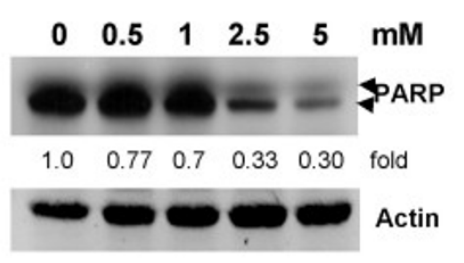

D

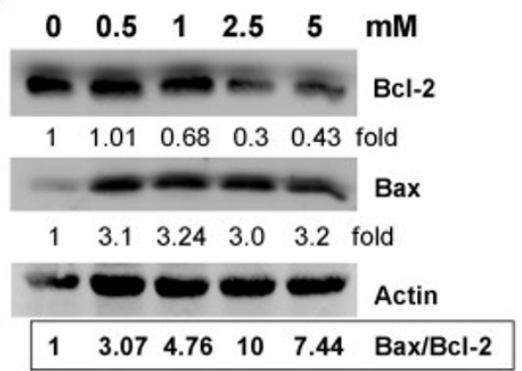

$48 \mathrm{hr}$ LA (mM) treatment

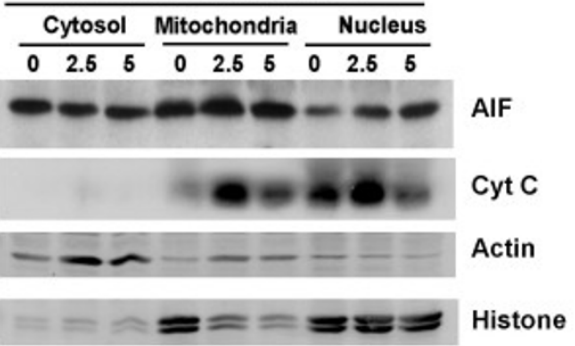

\section{Figure 3}

Induction of apoptosis by LA and analysis on poly(ADP-ribose) polymerase (PARP) cleavage, AIF/cytochrome c expression, and bax/bcl-2 ratio and subcellular distribution of AIF/cytochrome c by LA. (A) HL-60 cells were treated with $0,2.5$ and 5 mM LA for 24 to 48 h; LA induced cell death, evident by the flow cytometric measured sub-GI fraction was calculated and shown as \% of total cell population. (B) Western blot analysis revealed down regulation of PARP expression at accompanied by appearance of $89 \mathrm{kDa}$ cleaved PARP fragment in $\geq 2.5 \mathrm{mM}, 48 \mathrm{~h}$ LA treated cells. (C) AIF and cytochrome c (Cyt C) expression in $48 \mathrm{~h}$ LA treated cells. (D) The actin-adjusted level of bax and bcl-2 and changes in the ratio of bax to bcl-2 in HL-60 cells treated for $48 \mathrm{~h}$ with increasing dose of LA. (E) Subcellular distribution of immunoreactive AIF and Cyt C in the cytosol, mitochondria and nucleus in control and 24 and $48 \mathrm{~h}$ LA-treated HL-60 cells. Actin and histone was used as loading control for cytosol and nucleus fractions, respectively. For mitochondria fraction verification was performed as detailed in Methods. 
tional support, other apoptosis markers including AIF, cytochrome $\mathrm{c}$ and bax/bcl-2 ratio were also examined to further ascertain the response of cells to LA treatment, by western blot analysis. Treatment of HL-60 cells with 2.5 $\mathrm{mM}$ LA for $24 \mathrm{~h}$ resulted in a 1.5 fold increase in total cytochrome $\mathrm{c}$, while the total AIF levels remained unchanged (Fig. 3C). As bcl-2 plays an integral role in the release of cytochrome c during cell death, we determined its expression and correspondingly, also bax, an apoptosis agonist, in control and LA-treated whole cell extracts. Western blot analysis clearly showed a dose-dependent suppression of bcl-2 expression, accompanied by concomitant increases in bax, in LA-treated cells, compared to control cells (Fig. 3D), which was most vividly illustrated as a marked increase in bax-to-bcl-2 expression ratio (Fig. 3D). These results further support the ability of LA to activate the mitochondria-dependent apoptotic cascade.

\section{LA induces translocation of cytochrome $c$ and AIF}

Induction of apoptosis by LA conceivably may involve the translocation of cytochrome $\mathrm{c}$ and AIF. This possibility was tested by biochemically fractionating different subcellular compartments and quantifying the appearance of cytochrome $\mathrm{c}$ and AIF by western blot analysis, following treatment with LA. Typical results in cells treated with 2.5 and $5 \mathrm{mM}$ LA for 24 and $48 \mathrm{~h}$ showed a spatiotemporal release of AIF from mitochondria into the nucleus (Fig. 3E). Similarly, cytochrome c was also apparently released from the mitochondria, and unexpectedly, was not accompanied by a concomitant cytoplasmic increase (Fig. $3 \mathrm{E})$. These results suggest that LA-elicited cell death may not occur via a classical cytochrome $\mathrm{c}$ mitochondriacytosol translocation mechanism but rather, a caspaseindependent mode of cell death via the nucleus directed shuttling of AIF and cytochrome c.

\section{Discussion}

LA has pleiotropic pharmacologic effects. The therapeutic potential of LA in cancer treatment has been shown in several studies $[14,17,20]$, however, the mechanisms by which LA elicits its chemopreventive properties remain largely unknown. Using HL-60 cells, we have confirmed the cancer cell growth suppressive effects of LA. Further, we now provide evidence for two novel LA-elicited changes that possibly contribute to its chemopreventive potentials: (i) LA induces blockade at both well established cell cycle checkpoint, respectively, $G_{1} / S$ and $G_{2} / M$, (ii) LA promotes the demise of treated HL-60 cells, possibly by a combination of mechanisms that includes the mitochondria-dependent apoptotic cascade encompassing a caspase-independent mode of cell death mediated via the translocation of AIF/cytochrome c. The proposed mechanism of LA is depicted in Figure 4.
Targeting dual checkpoints of the cell cycle by LA is particularly noteworthy as it effectively, as a single agent, accomplishes the same cellular endpoint as what has been eloquently proposed by $\mathrm{Li}$ et al [30] of inducing malignant cell demise through the deliberate bi-checkpoint blockade-mediated induction of apoptosis, as exemplified by the combined administration of $\beta$-lapachone and taxol to deliver a one-two punch for tumor cell killing and eradication. The mechanism by which LA acts in dual cell cycle checkpoint control may be complex and appears to involve at least the down regulation of cyclin $\mathrm{E} / \mathrm{cdk} 2$ and cyclin $\mathrm{B} 1 / \mathrm{cdk} 1$ in a manner that effects synergistic cell cycle arrest and induction of apoptosis [30,31]. It is notable that earlier studies have also demonstrated the posttranslational elevation of p27Kip1 and p21Cip1 as specific LA elicited effects $[14,19]$. Taken together, these results not only reinforce the essential role of LA in cell cycle control but are likely to be directly involved in contributing to its therapeutic potential in cancer treatment.

Results of flow cytometry analysis assessing the presence of cells with fractional DNA content (evident as the sub$G_{1}$ peak), in combination with the appearance of specifically processed $89-\mathrm{kD}$ PARP product as demonstrated by immunoblot analysis (Figures 2 and 3), showed clearly the restoration/activation of programmed cell death in HL-60 cells treated with LA. Since the flow cytometric data appeared to show a more pronounced effect of prolonged treatment by LA, especially at the higher concentrations it is possible that more than one mode of cell death is triggered by LA. Equally likely is the possibility that these two assays alone are not sufficiently definitive to establish the mode of cell death in the treated cells. Experiments exploring TUNEL and agarose gel electrophoresis for detecting appearance of DNA ladders, and the use of caspase inhibitors are contemplated to address these and other possibilities. Despite the limitations mentioned above, it is important to point out a significant finding in this study, i.e., the demonstration of translocation of two proteins, respectively, AIF and cytochrome c from mitochondria to the nucleus after LA treatment. A dosedependent increase of AIF appearing in the nuclear fraction was observed as early as $24 \mathrm{~h}$, whereas cytochrome c release and nuclear accumulation occurred at $48 \mathrm{~h}$. Recent studies have demonstrated that AIF plays a critical role in caspase-independent induction of apoptosis $[32,33]$. Our studies also showed that LA down regulated bcl-2 expression, which in turn may aid the release of AIF by altering mitochondrial permeability and contributing to its relocalization to the nucleus, and thereby promoting the induction of caspase-independent apoptosis. A companion and equally important change in this regard may be the cellular fate of cytochrome c, which, in our studies of the effects of LA, became nuclear bound. It is notable that previous studies have demonstrated a novel role of cyto- 


\section{A. Cell cycle control by LA}

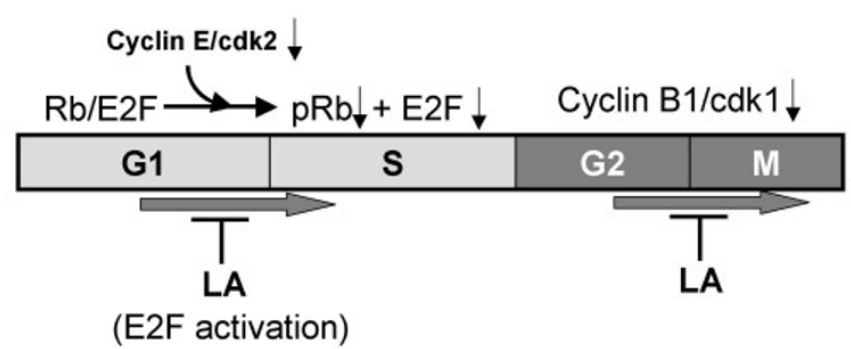

\section{B. Induction of apoptosis by LA}

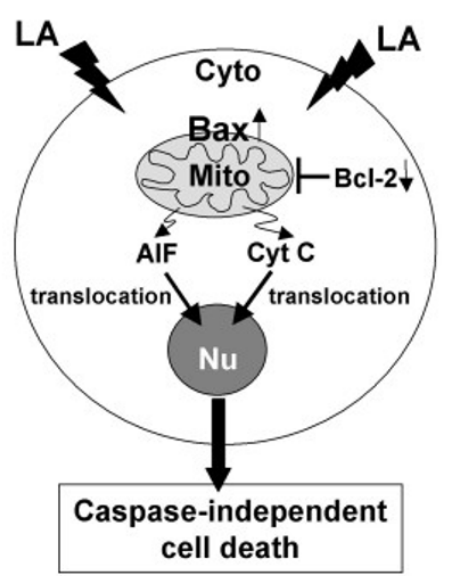

\section{Figure 4}

Proposed mechanism of action of LA. In this model, the ability of LA to suppress cell proliferation and induce apoptosis in HL60 cells is hypothesized to involve $(A)$ disruption of cell cycle control, (B) perturbation in apoptogenic/anti-apoptotic (bax/bcl2) regulatory protein expression and translocation of mitochondrial AIF and cytochrome c (Cyt C) from mitochondria to nucleus and promoting the caspase-independent induction of apoptosis.

chrome $\mathrm{c}$ in the activation caspase-independent apoptosis, as involving the nucleus accumulation of cytochrome c instead of a more generally accepted classical mechanism in which the cytoplasmic translocation of cytochrome $\mathrm{c}$ from mitochondria provides a key trigger for caspase-dependent apoptosis [34]. Indeed, there is increasing awareness and acceptance regarding the coexistence of caspase-dependent and caspase-independent apoptotic and other modes of cell death for a given cell type [35]. Such as notion is consistent with and supported by our observation of the re-localization of mitochondrial proteins, AIF and cytochrome c into nucleus by LA treatment, suggesting that LA signals cell death in responsive cells by a caspase-independent, nuclear activated other apoptotic and perhaps other cell death mechanism.
Importantly, the concentrations of LA used in this study are similar to those used in other in vitro studies reporting the cell cycle arrest and apoptosis inducing properties of LA [19]. Notably also, mM LA concentrations have been reported in the plasma after oral dosing in pharmacokinetic studies and are considered non-toxic. Moreover, the half-life of LA in plasma is short (30 min), suggesting that it is rapidly taken up into tissues or further metabolized [36]. Therefore, it is plausible that high concentrations, in the $\mathrm{mM}$ range, may accumulate in target tissues.

\section{Conclusion}

The results of this study demonstrate conclusively that LA treatment causes cell cycle arrest and alterations in the expression/translocation of mitochondrial apoptogenic/ anti-apoptotic proteins including AIF and cytochrome c, and the net result being a reduction in cell proliferation 
concomitant with cell cycle arrest and induction of apoptosis. These findings may be part of the mechanisms that underlie or contribute to the beneficial effects of this readily available dietary supplement in cancer prevention.

\section{Authors' contributions}

ES carried out the studies in Figure 1, Figure 2B and 2C, and Figure 3B-E, TCH carried out the studies in Figure 2A, Figure 3A and Figure 4, TCH conceived of the study, and participated in its design and coordination. All authors read and approved the final manuscript.

\section{Acknowledgements}

We thank Dr. Joseph Wu for helpful discussions and Jan Kunicki for assistance in flow cytometry analysis.

\section{References}

I. Perham RN, Jones DD, Chauhan HJ, Howard MJ: Substrate channelling in 2-oxo acid dehydrogenase multienzyme complexes. Biochem Soc Trans 2002, 30:47-5I.

2. Packer L, Witt EH, Tritschler HJ: alpha-Lipoic acid as a biological antioxidant. Free Radic Biol Med 1995, 19:227-250.

3. Packer L, Tritschler HJ, Wessel K: Neuroprotection by the metabolic antioxidant alpha-lipoic acid. Free Radic Biol Med 1997, 22:359-378.

4. Bast $A$, Haenen GR: Lipoic acid: a multifunctional antioxidant. Biofactors 2003, 17:207-213.

5. Jones W, Li X, Qu ZC, Perriott L, Whitesell RR, May JM: Uptake, recycling, and antioxidant actions of alpha-lipoic acid in endothelial cells. Free Radic Biol Med 2002, 33:83-93.

6. Packer L, Kraemer K, Rimbach G: Molecular aspects of lipoic acid in the prevention of diabetes complications. Nutrition 200I, 17:888-895.

7. Wollin SD, Jones PJ: Alpha-lipoic acid and cardiovascular disease. J Nutr 2003, 1 33:3327-3330.

8. Duenschede F, Erbes K, Kircher A, Westermann S, Schad A, Riegler N, Ewald P, Dutkowski P, Kiemer AK, Kempski O, Junginger T: Protection from hepatic ischemia/reperfusion injury and improvement of liver regeneration by alpha-lipoic acid. Shock 2007, 27:644-65I.

9. Bilska A, Wlodek L: Lipoic acid - the drug of the future? Pharmacol Rep 2005, 57:570-577.

10. Lee EY, Lee CK, Lee KU, Park JY, Cho KJ, Cho YS, Lee HR, Moon SH, Moon HB, Yoo B: Alpha-lipoic acid suppresses the development of collagen-induced arthritis and protects against bone destruction in mice. Rheumatol lnt 2007, 27:225-233.

II. Manda K, Ueno M, Moritake T, Anzai K: Radiation-induced cognitive dysfunction and cerebellar oxidative stress in mice: protective effect of alpha-lipoic acid. Behav Brain Res 2007, I77:7-14.

12. Smith AR, Shenvi SV, Widlansky M, Suh JH, Hagen TM: Lipoic acid as a potential therapy for chronic diseases associated with oxidative stress. Curr Med Chem 2004, I I: | | 35- | | 46.

13. Patrick L: Nutrients and HIV: part three - $\mathbf{N}$-acetylcysteine, alpha-lipoic acid, L-glutamine, and L-carnitine. Altern Med Rev 2000, 5:290-305.

14. Simbula G, Columbano A, Ledda-Columbano GM, Sanna L, Deidda M, Diana A, Pibiri M: Increased ROS generation and $\mathrm{p} 53$ activation in alpha-lipoic acid-induced apoptosis of hepatoma cells. Apoptosis 2007, 1 2:113-123.

15. Ho YS, Lai CS, Liu HI, Ho SY, Tai C, Pan MH, Wang Y]: Dihydrolipoic acid inhibits skin tumor promotion through antiinflammation and anti-oxidation. Biochem Pharmacol 2007, 73:1786-1795.

16. Pack RA, Hardy K, Madigan MC, Hunt NH: Differential effects of the antioxidant alpha-lipoic acid on the proliferation of mitogen-stimulated peripheral blood lymphocytes and leukaemic T cells. Mol Immunol 2002, 38:733-745.

17. Wenzel U, Nickel A, Daniel H: alpha-Lipoic acid induces apoptosis in human colon cancer cells by increasing mitochondrial respiration with a concomitant O2-*-generation. Apoptosis 2005, 10:359-368.

18. Vig-Varga E, Benson EA, Limbil TL, Allison BM, Goebl MG, Harrington MA: Alpha-lipoic acid modulates ovarian surface epithelial cell growth. Gynecol Oncol 2006, 103:45-52.

19. van de Mark K, Chen JS, Steliou K, Perrine SP, Faller DV: Alphalipoic acid induces p27Kip-dependent cell cycle arrest in nontransformed cell lines and apoptosis in tumor cell lines. J Cell Physiol 2003, 194:325-340.

20. Moungjaroen J, Nimmannit U, Callery PS, Wang L, Azad N, Lipipun V, Chanvorachote $P$, Rojanasakul $Y$ : Reactive oxygen species mediate caspase activation and apoptosis induced by lipoic acid in human lung epithelial cancer cells through Bcl-2 down-regulation. J Pharmacol Exp Ther 2006, 31 9:1062-1069.

2I. Sen CK, Sashwati R, Packer L: Fas mediated apoptosis of human Jurkat T-cells: intracellular events and potentiation by redox-active alpha-lipoic acid. Cell Death Differ 1999, 6:48I-49I.

22. Flier J, Van Muiswinkel FL, Jongenelen CA, Drukarch B: The neuroprotective antioxidant alpha-lipoic acid induces detoxication enzymes in cultured astroglial cells. Free Radic Res 2002, 36:695-699.

23. Cao Z, Tsang M, Zhao H, Li Y: Induction of endogenous antioxidants and phase 2 enzymes by alpha-lipoic acid in rat cardiac H9C2 cells: protection against oxidative injury. Biochem Biophys Res Commun 2003, 3 1 0:979-985.

24. Ogborne RM, Rushworth SA, O'Connell MA: Alpha-lipoic acidinduced heme oxygenase-I expression is mediated by nuclear factor erythroid 2-related factor 2 and p38 mitogenactivated protein kinase in human monocytic cells. Arterioscler Thromb Vasc Biol 2005, 25:2100-2105.

25. DiPietrantonio AM, Hsieh TC, Wu JM: Specific processing of poly(ADP-ribose) polymerase, accompanied by activation of caspase-3 and elevation/reduction of ceramide/hydrogen peroxide levels, during induction of apoptosis in host HL-60 cells infected by the human granulocytic ehrlichiosis (HGE) agent. IUBMB Life 2000, 49:49-55.

26. Hsieh TC, Kunicki J, Darzynkiewicz Z, Wu JM: Effects of extracts of Coriolus versicolor (I'm-Yunity) on cell-cycle progression and expression of interleukins- I beta,-6, and -8 in promyelocytic HL-60 leukemic cells and mitogenically stimulated and nonstimulated human lymphocytes. J Altern Complement Med 2002, 8:59l-602.

27. Hsieh TC, Wu P, Park S, Wu JM: Induction of cell cycle changes and modulation of apoptogenic/anti-apoptotic and extracellular signaling regulatory protein expression by water extracts of I'm-Yunity (PSP). BMC Complement Altern Med 2006, 6:30.

28. DiPietrantonio AM, Hsieh TC, Olson SC, Wu JM: Regulation of G I/ $S$ transition and induction of apoptosis in HL-60 leukemia cells by fenretinide (4HPR). Int $J$ Cancer 1998, 78:53-6I.

29. Darzynkiewicz Z, Bedner E, Smolewski P: Flow cytometry in analysis of cell cycle and apoptosis. Semin Hematol 200I, 38: $179-193$.

30. Li Cl, Li YZ, Pinto AV, Pardee AB: Potent inhibition of tumor survival in vivo by beta-lapachone plus taxol: combining drugs imposes different artificial checkpoints. Proc Natl Acad Sci U SA 1999, 96:13369-13374.

31. Evan G, Littlewood T: A matter of life and cell death. Science 1998, 281 : 1317-1322.

32. Daugas E, Nochy D, Ravagnan L, Loeffler M, Susin SA, Zamzami N, Kroemer G: Apoptosis-inducing factor (AIF): a ubiquitous mitochondrial oxidoreductase involved in apoptosis. FEBS Lett 2000, 476: I I8-123.

33. Lipton SA, Bossy-Wetzel E: Dueling activities of AIF in cell death versus survival: DNA binding and redox activity. Cell 2002, III:I47-I50.

34. Nur EKA, Gross SR, Pan Z, Balklava Z, Ma J, Liu LF: Nuclear translocation of cytochrome c during apoptosis. J Biol Chem 2004, 279:249||-249|4.

35. Kroemer G, Martin SJ: Caspase-independent cell death. Nat Med 2005, I I:725-730.

36. Teichert J, Kern J, Tritschler HJ, Ulrich H, Preiss R: Investigations on the pharmacokinetics of alpha-lipoic acid in healthy volunteers. Int J Clin Pharmacol Ther 1998, 36:625-628. 